\title{
Hydrogen sulfide, nitric oxide, and neurodegenerative disorders
}

\author{
Sandesh Panthi ${ }^{*}$, Sumeet Manandhar ${ }^{2}$ and Kripa Gautam ${ }^{3}$
}

\begin{abstract}
Hydrogen Sulfide $\left(\mathrm{H}_{2} \mathrm{~S}\right)$ and Nitric Oxide (NO) have become recognized as important gaseous signaling molecules with enormous pharmacological effects, therapeutic value, and central physiological roles. NO is one of the most important regulators of the pathophysiological condition in central nervous system (CNS). It is critical in the various functioning of the brain; however, beyond certain concentration/level, it is toxic. $\mathrm{H}_{2} \mathrm{~S}$ was regarded as toxic gas with the smell like rotten egg. But, it is now regarded as emerging neuroprotectant and neuromodulator. Recently, the use of donors and inhibitors of these signaling molecules have helped us to identify their accurate and precise biological effects. The most abundant neurotransmitter of CNS (glutamate) is the initiator of the reaction that forms $\mathrm{NO}$, and $\mathrm{H}_{2} \mathrm{~S}$ is highly expressed in brain. These molecules are shedding light on the pathogenesis of various neurological disorders. This review is mainly focused on the importance of $\mathrm{H}_{2} \mathrm{~S}$ and $\mathrm{NO}$ for normal functioning of CNS.
\end{abstract}

Keywords: Hydrogen sulfide, Nitric oxide, Central nervous system, Gasotransmitters, Gaseous signaling molecules, Neurodegeneration, Neurodegenerative disorders

\section{Background}

The discovery of gaseous signaling molecules like $\mathrm{H}_{2} \mathrm{~S}$, NO, and Carbon monoxide (CO) added a new era in biomedical science as these molecules have great importance in mammalian physiology [1]. They have been termed as 'gasotransmitters' as they are either internally produced or synthesized (endogenously) in the organism or are received from the atmosphere and transmit chemical signals thereby promote or induce various physiological changes inside mammalian body [2]. The term 'gasotransmitter' for these molecules was firstly introduced in 2002, and these molecules share some common characteristics. They are endogenously produced, enzymatically generated, and their production can be regulated. Gasotransmitters are permeable to the cell membrane, but their functions inside the body are dependent on their concentration [3, 4]. For better understating and to boost biomedical research in the field of gasotransmitters, a society named European Network on Gasotransmitters was established in 2011.

Nitric oxide was the first gaseous molecule to be linked with its beneficial roles [5]. NO was the molecule of the year in 1992 [6] in journal 'Science' and was recognized by

\footnotetext{
* Correspondence: sanpan276@gmail.com; superbsynergy@gmail.com 'Otago School of Biomedical Sciences, University of Otago, Dunedin, New Zealand Full list of author information is available at the end of the article
}

Nobel Prizes for Medicine/Physiology in 1998 [7]. Because of its toxic nature and noxious effects, beneficial roles of this molecule were previously neglected [8]. CO was the second to be discovered as neurotransmitters, and it has proved its importance in cardiovascular and neuronal functioning $[9,10]$. However, the recognition of endogenous level of $\mathrm{H}_{2} \mathrm{~S}$ in mammalian tissue, confirmed the existence of this gasotransmitters [11-13]. Synthesis, functions, and the role of these gasotransmitters in various physiological aspect is discussed in previous reviews [14-19]. The primary purpose of this review is to highlight the contextual link between CNS and these gaseous signaling molecules.

\section{NO and CNS}

NO is synthesized in CNS from an amino acid called as L-arginine via an enzyme called NO-synthase (NOS) in equimolar amounts with L-citrulline [20, 21]. There are three different isoforms of NOS which are genetically different $[22,23]$. Expression of NOS in various part of the brain is shown in Table 1 . Because of its ability to passively permeate cell membrane via diffusion, there is no need of receptor binding unlike conventional neurotransmitter signaling pathways [24]. Its key potential to diffuse rapidly in aqueous and lipid environment made it unique from other CNS signaling molecules [25]. 
Table 1 Expression of NOS in various part of brain

\begin{tabular}{ll}
\hline Isoforms of NOS & Expression of NOS \\
\hline eNOS & Vascular endothelium, Choroid plexus \\
nNOS & $\begin{array}{l}\text { Neuronal cell bodies especially in thalamus, } \\
\text { olfactory bulb, claustrum, amygdala, cortex, } \\
\text { hippocampus, hypothalamus } \\
\text { iNOS }\end{array}$ \\
\hline
\end{tabular}

$\mathrm{NO}$ is mainly produced by Neuronal NO-synthase (nNOS) and Endothelial NO-synthase (eNOS) under normal physiological conditions, but Inducible NO-synthase (iNOS) is only generated after induction via inflammatory mediators like cytokines and endotoxins [26]. nNOS was the first isoform to be purified and cloned from the brain [27]. NO diffuses from one neuron to another. It is not stored in any kind of synaptic vesicles, and its release is independent to membrane depolarization [25, 28]. The generation of $\mathrm{NO}$ is similar for all subtypes of NOS, but the functional regulation and level of production is different. nNOS and eNOS are constitutive forms of NOS, and both rely on the elevation of intracellular $\mathrm{Ca}^{2+}$ level to initiate $\mathrm{NO}$ synthesis. nNOS requires $\mathrm{N}$ methyl-D-aspartate (NMDA) receptor activation, and eNOS needs calmodulin-dependent displacement of regulatory proteins for NO synthesis. However, iNOS activity is less sensitive to changes in intracellular $\mathrm{Ca}^{2+}$. But, it can produce a large amount of $\mathrm{NO}$ compared to that of $\mathrm{NO}$ associated with eNOS and nNOS [29].

The signal transduction of NO in the target cell is associated with soluble Guanylate cyclase (GC)/Cyclic-guanosine mono phosphate (cGMP) (Fig. 1) or with S-nitrosylation of protein [30]. NO binds with the cGMP producing enzyme called as GC and expresses its modulating effects as pre-or post-synaptic retrograde messenger which facilitates glutamatergic neurotransmission and acts as a neuromodulator of excitatory neurotransmitter [28, 31]. Recent researches also demonstrated the effect of NO on inhibitory GABAergic synaptic transmission [32] via cGMP dependent suppression of potassium/chloride co-transporter [33].

Reduction of NO may lead to the inability of patients to learn and memorize due to the impairment of long-term potentiation (LTP), as NO is responsible for the increment of the synaptic efficiency of pre-synaptic glutamatergic neurons and this increment induces LTP [34]. This gaseous signaling molecule also exerts protective role in brain-ischemia reperfusion injury as a result of its strong stimulatory effect on angiogenesis and vasodilation [35].

Hemodynamic and vasodilation activity of $\mathrm{NO}$ donors $[S$ nitrosoglutathione (GSNO), $S$-nitroso- $N$-acetyl-penicillamine (SNAP), sodium nitroprusside (SNP), methylamine hexamethylene methylamine NONOate (MAHMA), propylamine propylamine NONOate (PAPA), 3-morpholinosydnonimine (SIN-1), and nitroglycerin (NTG)] has also provided cerebrovascular neuroprotective role in the various experimental model of stroke [36, 37]. NO produced from endothelial cells and adrenergic neurons regulates cerebral blood flow and smooth muscle tone during conditions like hypoxia, hypercapnia, hyperoxia, etc. eNOS mediates the basal release of NO to regulate the cerebral blood flow in various mammals. This role of $\mathrm{NO}$ has been confirmed by various recent researches using NOS inhibitors [38-40].

Age-related decrease in cGMP was also linked with increased NOS level in one recent study which may be helpful for anti-aging therapies [41]. NO is also suspected to be a crucial molecule to nitrate/S-nitrosylate brain-derived neurotrophic factor (BDNF) and tropomyosin-related kinase receptor which helps the maintenance of synaptic plasticity

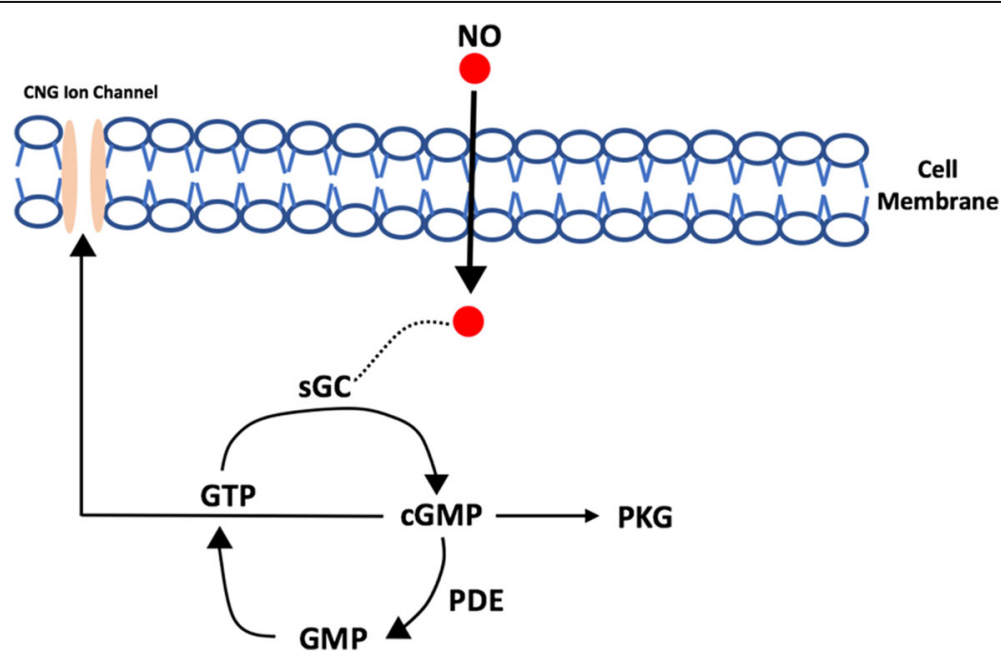

Fig. 1 NO-cGMP signaling pathway: Highly membrane permeable NO binds with NO-soluble Guanylyl cyclase (sGC) which causes conformational changes, and it induces the conversion of GTP-cGMP. cGMP interacts with various intracellular proteins like phosphodiesterase (PDE), cGMP-gated channels (CNG) and protein kinase G (PKG) which stimulates various downstream substrates. Other various pathways are triggered, and many physiological effects starts in cellular level. (Figure adapted and modified from [31]) 
and LTP [42]. A study has found that NO directly activates ryanodine receptor (RyR), which cause the intracellular release of $\mathrm{Ca}^{2+}$ to towards CNS, and it is believed to promote the prolonged $\mathrm{Ca}^{2+}$ signaling in the brain. Alike, BDNF and tropomyosin-related kinase receptor, this process is also triggered by reversible $S$-nitrosylation that cause the $\mathrm{Ca}^{2+}$ release. This whole process is essential for cerebellar synaptic plasticity [43]. Role of NO in maintaining cerebellar synaptic plasticity, synaptic transmission efficiency, and cerebellar LTP are also studied and mentioned [44-46].

$\mathrm{NO}$ was also found to have affect in the sleep-wake cycle. Intraperitoneal (i.p.) administration of nNOS inhibitor caused the drop in rapid eye movement (REM) and sleepwave-sleep. This relationship between the production of $\mathrm{NO}$ and sleep is also thought to be linked with various neurodegenerative disorders [47]. Researchers linked the role of $\mathrm{NO}$ with experimental seizure model where overstimulation of NMDA receptors is believed to cause the prolonged release of NO [48]. However, the overactivity of same NMDA receptors leading overproduction of NO may contribute to cell death-initiating various neurodegenerative conditions like Alzheimer's disease (AD), Parkinson's disease (PD), amyotrophic lateral sclerosis (ALS), stroke and inhibition of NOS could be neuroprotective [49].

Brain hypoperfusion and increased vascular oxidative stress are the common phenomena involved in $\mathrm{AD}$ [50, 51]. Few researchers also found that abnormal nNOS expressions are early symptoms of the $\mathrm{AD}$ and cognitive impairment involved in $\mathrm{AD}[52,53]$. It was found that imbalance between the nitrotyrosine and all three isoforms of NOS results in the increased amount of nitrosylation and oxidative products in blood and CSF of AD patients [54]. Some more physiological roles of the different isoform of NOS are listed in Table 2.

Stroke (ischemic stroke) is also characterized by interruption of blood flow in the cerebral artery which ultimately result in ischemia and tissue death. Using the experimental animal model of stroke, Huang et al. in 1996 found that eNOS deficient mice has bigger infracts than wild type [55]. eNOS was also found to maintain the level of cerebral blood flow (CBF) after traumatic brain injury (TBI). However, eNOS knock-out mice has greater

Table 2 Physiological roles of different isoform of NOS

\begin{tabular}{|c|c|}
\hline Isoforms of NOS & Functions \\
\hline \multirow[t]{3}{*}{ eNOS } & $\begin{array}{l}\text { - Preservation and maintenance of } \\
\text { brain's microcirculation [21]. }\end{array}$ \\
\hline & • Inhibition of platelet aggregation [131]. \\
\hline & - Reduction of smooth muscle proliferation $[21,39]$ \\
\hline nNOS & $\begin{array}{l}\text { Important roles in memory formation, CNS blood } \\
\text { flow, neuronal plasticity, transmission of pain } \\
\text { signals [21]. }\end{array}$ \\
\hline iNOS & $\begin{array}{l}\text { Response to proinflammatory cytokines or } \\
\text { endotoxins [21]. }\end{array}$ \\
\hline
\end{tabular}

reduction of CBF after TBI $[56,57]$. Various studies have also proved that $\mathrm{NO}$ depletion has a critical role in cortical spreading depression, early brain injury, microthrombus formation, changes in blood flow after subarachnoid hemorrhage and if we can target this pathway, then it is possible to prevent secondary neuronal injury [21].

Interestingly, inhaled and intravenous (i.v.) injection of sodium nitrite (NO donor) was found to have neuroprotective role in mice and rats during cardiac arrest (seen in the clinical model of ischemia/reperfusion) [58, 59]. Not only in the mice model of ischemia, but there are also few studies conducted till now which support that inhaled $\mathrm{NO}$ or $\mathrm{i} / \mathrm{v}$ injected of L-arginine or sodium nitrite has protective outcomes in the development of brain after injury, using various experimental injury models [60-67]. This gasotransmitter is also associated to normalize capillary blood flow, improvement of delivery of oxygen [68], prevention and reversal of cerebral vasospasm $[21,66,67]$, mitochondrial respiration [58], development of healthy brain [21], myelination [69], and protective role after peripheral nerve injury [15].

However, evidence suggests that higher concentration of NO can impact neuronal death in several ways. Neuronal death may occur due to energy depletion-induced necrosis that may stop mitochondrial respiration or slow inhibition of glycolysis. So, the role of NO is particularly dependent on its concentration, time-course exposure, and presence/absence of ROS at particular level and cells. Thus, being a neuroprotectant at low level, NO might behave as toxicant at higher concentration [70]. It was found that after the administration of nitro-L- arginine, the infarct size of nNOS-KO mice became larger (whereas vascular NO protects after middle cerebral artery occlusion) and NO induced calcium release was found to be involved in neuronal cell death $[43,71]$. Because of this reason NO is often termed as a "double-edged sword" [48]. One study revealed the critical role of NO during neurodegenerative disorders and brain aging can form blood-cerebrospinal fluid barrier and this may interfere choroid-plexus gateway activity [72]. Similarly, another finding stated $\mathrm{NO}$ as the negative player in the progression of pathological nature of $\mathrm{AD}$ [73]. Recently, another deleterious role of NOS with involvement of CNS in mouse model of dengue has been discovered [74]. NO is involved in various physiological functioning which is explained earlier in this review, however, if the physiological control of signaling pathways involved with NO or NOS fails, then NO and other reactive nitrogen species (RNS) can cause neuroinflammation and neurodegeneration [75].

\section{$\mathrm{H}_{2} \mathrm{~S}$ and CNS}

$\mathrm{H}_{2} \mathrm{~S}$ is a toxic and poisonous gas having an odour of rotten eggs. Alike other gasotransmitters, the physiological role of $\mathrm{H}_{2} \mathrm{~S}$ was overlooked or not paid attention due to its toxicity [76]. It is the most recent gaseous signaling molecule discovered after $\mathrm{NO}$ and $\mathrm{CO}$ having enormous pathophysiological 
significance in various disease and conditions [77]. It is sulfur analog of water, and because of its weak intermolecular force, it exists in gaseous form [78]. It is synthesized via both enzymatic and non-enzymatic pathways inside mammalian tissue, but non-enzymatic route accounts for a small portion. Cystathionine $\beta$-synthase (CBS) and Cystathionine $\gamma$-lyase (CSE) are two enzymes responsible for biosynthesis of $\mathrm{H}_{2} \mathrm{~S}$ from L-cysteine [79, 80]. 3-mercaptopyruvate sulfurtransferase (3MST) is another enzyme that can generate $\mathrm{H}_{2} \mathrm{~S}$ through cys-catabolism pathway. CSE and CBS are localized in the cytoplasm of cell, but 3MST is expressed partly in mitochondria and cytoplasm $[81,82]$. A recent study showed $\mathrm{H}_{2} \mathrm{~S}$ could be produced from D-cysteine via enzyme Damino acid oxidase (DAO) [83, 84]. Non-enzymatically, it can be produced from thiosulfate [14] and glucose (via glycolysis) or from phosphogluconate via NADPH oxidase $[85,86]$. Although $\mathrm{H}_{2} \mathrm{~S}$ has beneficial roles in various hematologic diseases, urological disease, cardiovascular functioning and oxidative stress, the effect of $\mathrm{H}_{2} \mathrm{~S}$ in CNS has attracted a lot of attention over the past few years [14, 77, 87]. Expression of different $\mathrm{H}_{2} \mathrm{~S}$ producing enzymes in various parts of mammalian tissues is listed in Table 3 [88]. Important signaling events of $\mathrm{H}_{2} \mathrm{~S}$ in various neuronal cells/ cell lines are listed below [89]:

1. Inhibition of monoamine oxidase (via catecholamines)

2. NMDA potentiation (via glutamate)

3. Cystic fibrosis transmembrane conductance regulator (CTFR) channel activation (via chloride channels)

4. $\mathrm{K}_{\mathrm{ATP}}$ and $\mathrm{K}_{\mathrm{Ca} 2+}$ channel activation (via potassium channels)

5. Intracellular calcium mobilisation, L-type and T-type channel activation (via calcium channels)

6. Supression of various types of neuronal toxicity (via oxidative stress)

7. Inhibition of p38-MAPK (via mitogen and tyrosine kinase receptors)

8. Stimulation of PKA and elevation of cAMP (via PKA)

$\mathrm{AD}$, a common form of dementia, characterized by memory impairment, personality changes, and various

Table 3 Expression of different $\mathrm{H}_{2} \mathrm{~S}$ producing enzymes in various parts of mammalian tissues

\begin{tabular}{ll}
\hline $\mathrm{H}_{2} \mathrm{~S}$ producing enzymes & Expression \\
\hline $\mathrm{CSE}$ & Liver, Kidney, Aorta, lleum but weakly \\
& found in brain. \\
CBS & Liver, Kidney, and Brain (astrocytes) \\
3MST & Liver, Kidney, Heart, Brain (Purkinje cells of \\
& cerebellum, pyramidal neurons of cerebellar \\
& cortex, hippocampus, mitral cells of olfactory \\
& bulb, retinal neurons), Vascular endothelium, \\
& Smooth muscle. \\
\hline
\end{tabular}

neuropsychiatric symptoms which cause neuronal apoptosis, neuronal inflammation (induced by amyloid- $\beta$ ), and increased oxidative stress [90-93]. Level of $\mathrm{H}_{2} \mathrm{~S}$ in the brain of patient with $\mathrm{AD}$ is lower than healthy people of same age [94]. A recent study revealed that in a rat model of vascular dementia, plasma $\mathrm{H}_{2} \mathrm{~S}$ level was lower and i.p. injection of $\mathrm{NaHS}\left(\mathrm{H}_{2} \mathrm{~S}\right.$ donor) protected neuronal injury and improved behavioral (learning and memory) tests results [95]. Another study demonstrated that progression of AD was abrupted after treatment with spa-water rich of $\mathrm{H}_{2} \mathrm{~S}$ content [96]. Role of $\mathrm{H}_{2} \mathrm{~S}$ in the improvement of cognitive functioning, spatial learning and memory [96], and neuroprotective effects $[14,90,93,97]$ is also providing us hopes against the $\mathrm{AD}$.

PD is characterized by progressive degeneration of dopaminergic neurons in the substantia nigra of midbrain which is age-related and leads to the formation of Lewy bodies in soma of residual neurons $[77,98]$. Previous studies based on animal models found that inhalation or injection of $\mathrm{H}_{2} \mathrm{~S}$ donors prevented abnormalities related to PD (microglial activation or motor dysfunction) including neuroprotective, neuromodulatory, and therapeutic roles of $\mathrm{H}_{2} \mathrm{~S}$ in $\mathrm{PD}$ [99-101]. $\mathrm{H}_{2} \mathrm{~S}$-mediated anti-oxidative, antiinflammatory, anti-apoptotic, and pro-survival effects linked with PD is also reviewed in recent paper [102].

TBI is one of the most common causes of death among youth in today's world and is considered as a public health epidemic. Memory impairment and cognitive dysfunction are two immediate effects of TBI whereas rapid and extreme production of ROS are also associated with secondary neuronal injury after TBI [103-106]. Karimi et al. injected NaHS intraperitoneally and observed neuroprotective effect of $\mathrm{H}_{2} \mathrm{~S}$ in TBI induced impaired memory in rats [103]. Zhang et al. found $\mathrm{H}_{2} \mathrm{~S}$ as a neuromodulator by injecting same $\mathrm{H}_{2} \mathrm{~S}$ donor which decreased TBI induced lesion volume in brain [107]. NaHS proved to be the neuroprotective in various other pathological conditions [108112]. These studies are also supported by recent finding which showed dynamic changes in $\mathrm{CBS}$ and $\mathrm{H}_{2} \mathrm{~S}$ levels in various part of the brain in experimental TBI models [107].

Huntington's Disease (HD) is associated with neurotoxicity, behavioural changes, impairment of motor coordination, and oxidative stress. Paul et al. showed that there is a reduction of level of CSE in mammalian tissues with HD. They demonstrated that loss of CSE mediates degeneration of neuronal cells and progression of HD [113, 114]. Studies have shown that patients with Down Syndrome (DS) has the higher level of CBS compared to that of a normal individual. This overexpression of CBS is believed to be the cause of abnormal cognitive ability in children with DS and may lead to $\mathrm{AD}$ in $\mathrm{DS}$ adults. Overproduction of $\mathrm{H}_{2} \mathrm{~S}$ is also associated with ethylmalonic encephalopathy [115]. Some other neuroprotective [40,78, 116-118], neurotransmissive role (facilitation of the induction of hippocampal LTP) 
$[119,120]$ of $\mathrm{H}_{2} \mathrm{~S}$ and its role in protection of neurons from apoptosis, degeneration [121, 122] and oxidative stress [121] are also studied extensively and illustrated in Table 4.

\section{Interrelationship between $\mathrm{NO}$ and $\mathrm{H}_{2} \mathrm{~S}$}

Various studies have shown that these gasotransmitters potentiate or antagonize each other's effect in production, downstream of certain molecular target, and direct chemical interaction [123]. These gasotransmitters share the same signaling pathway in the regulation of angiogenesis and endothelium dependent vasorelaxation [124]. Few articles demonstrated the common pathway of these gasotransmitters in the mammalian cardiovascular system [2, $17,125,126]$. Additionally, $\mathrm{NO}$ and $\mathrm{CO}$ are also found to have link in vasorelaxation and stimulation of calcium sensitive potassium channels [123, 127].

Gasotransmitters also have a tendency to compete with each other. $\mathrm{CO}$ and $\mathrm{NO}$ have particular relationships with CBS. Research suggests that NO can block the enzymatic activity of $\mathrm{H} 2 \mathrm{~S}$ via binding with $\mathrm{CBS}$ and CBS has also high preference for CO. If eNOS is impeded, then it cancels out the angiogenic effects of $\mathrm{H}_{2} \mathrm{~S}$ whereas blocking $\mathrm{H}_{2} \mathrm{~S}$ significantly lowers the angiogenic effects of $\mathrm{NO}$. $\mathrm{CO}$ and $\mathrm{H}_{2} \mathrm{~S}$ act on the same molecular target but have opposite results. Even though $\mathrm{H}_{2} \mathrm{~S}, \mathrm{NO}$, and $\mathrm{CO}$ compete and share similar signaling pathways

Table 4 Physiological functions of $\mathrm{H}_{2} \mathrm{~S}$ based on its neuroprotective and neuromodulatory effects

\begin{tabular}{ll}
$\begin{array}{l}\text { Mode of physiological } \\
\text { functions of } \mathrm{H}_{2} \mathrm{~S}\end{array}$ & Evidences \\
\hline Neuroprotection & PD: Inhibits oxygen consumption and \\
6-hydroxydopamine evoked NADPH \\
oxidation. \\
Acts on various protein kinases. \\
HD: Upregulation of GSH enzyme and \\
reveals the learning and memory \\
problem. \\
AD: Decreases protein oxidation and \\
lipid peroxidation. \\
Reduces homocysteine-induced toxicity. \\
Influences synaptic remodelling. \\
ALS: Proper regulation of GSH enzyme \\
and reduction of oxidative stress. \\
TBI: Protection via apoptotic and \\
autophagic pathway. \\
Protective effects against neuropathic \\
pain and brain edema. \\
• Long term potentiation. \\
• CFTR Cl and KaTP cycle regulation. \\
• Enhancement of NMDA \\
receptor activity. \\
• Regulation of intracellular Ca ${ }^{2+}$. \\
\hline Neuromodulation
\end{tabular}

with each other, their interactions provide beneficial effects on mammalian physiology [14, 124, 128-130].

\section{Conclusions}

Current understandings and the published data in this field has made clear about their importance in the mammalian physiology and pathology. There are still many controversies surrounding the signaling pathways, beneficial roles, and harmful effects of these gasotransmitters. However, their role in mediation and modulation of cell-to-cell communication is globally accepted fact. Research and studies regarding these molecule is still in the preliminary stage in the field of biomedical science, and especially their role in CNS is relatively unexplored. Further research also should be focused on their combinatorial effect and signaling pathways regarding their antagonistic effect should be disclosed for the development of new therapeutic approaches for various neurological disorders.

\section{Abbreviations}

CBS: Cystathionine $\beta$-synthase; CSE: Cystathionine $\gamma$-lyase; 3MST: 3-Mercapto pyruvate sulfurtransferase; AD: Alzheimer's disease; ALS: Amyotrophic lateral sclerosis; BDNF: Brain derived neurotrophic factor; CAMP: Cyclic adenosine mono phosphate; CBF: Cerebral blood flow; CNS: Central nervous system; CO: Carbon mono-oxide; CTFR: Cystic fibrosis transmembrane conductance regulator; DAO: D-amino acid oxidase; DS: Downs syndrome;

eNOS: Endothelial nitric oxide synthase; GC: Guanylyl cyclase; $\mathrm{H}_{2} \mathrm{~S}$ : Hydrogen sulfide; HD: Huntington's disease; i.p.: Intraperitoneal; i.v.: Intravenous; iNOS: Inducible nitric oxide synthase; LTP: Long term potentiation; MAPK: Mitogen-activated protein kinase; NADPH: Nicotinamide adenosine dinucleotide phosphate; NMDA: N-methyl-D-aspartate; nNOS: Neuronal nitric oxide synthase; NO: Nitric oxide; NOS: Nitric oxide synthase; PD: Parkinson's disease; PKA: Protein kinase A; REM: Rapid eye movement; RyR: Ryanodine receptor; TBI: Traumatic brain injury

\section{Acknowledgements}

Not Applicable

Funding

Not Applicable

Availability of data and materials

Not Applicable

Authors' contributions

SP designed and planned about the review topic. SP wrote the manuscript. SM and KG provided intellectual input to the manuscript. All authors read and approved the final manuscript.

Ethics approval and consent to participate Not Applicable

Consent for publication

Not Applicable

Competing interests

The authors declare that they have no competing interests.

Author details

${ }^{1}$ Otago School of Biomedical Sciences, University of Otago, Dunedin, New Zealand. ${ }^{2}$ Department of Pharmacy, Chosun University, Gwangju, South Korea. ${ }^{3}$ China Medical University, Shenyang, People's Republic of China. 
Received: 21 December 2017 Accepted: 31 January 2018

\section{Published online: 13 February 2018}

\section{References}

1. Li L, Moore PK. An overview of the biological significance of endogenous gases: new roles for old molecules. Portland Press Limited. 2007;

2. Fukuto JM, Carrington SJ, Tantillo DJ, Harrison JG, Ignarro LJ, Freeman BA, et al. Small molecule signaling agents: the integrated chemistry and biochemistry of nitrogen oxides, oxides of carbon, dioxygen, hydrogen sulfide, and their derived species. Chem Res Toxicol. 2012;25:769-93.

3. Wang RUI. Two's company, three'sa crowd: can H2S be the third endogenous gaseous transmitter? FASEB J. 2002;16:1792-8.

4. Wang R. Signal transduction and the Gasotransmitters: $\mathrm{NO}, \mathrm{CO}$, and $\mathrm{H}_{2} \mathrm{~S}$ in biology and medicine. Springer Science \& Business Media; 2004.

5. Rajfer J, Aronson WJ, Bush PA, Dorey FJ, Ignarro LJ. Nitric oxide as a mediator of relaxation of the corpus cavernosum in response to nonadrenergic, noncholinergic neurotransmission. N Engl J Med Mass Medical Soc. 1992:326:90-4.

6. Cech TR, Bennett D, Jasny B, Kelner KL, Miller LJ, Szuromi PD, et al. The molecule of the year. Science. 1992;258:1861.

7. Zhou L, Zhu D-Y. Neuronal nitric oxide synthase: structure, subcellular localization, regulation, and clinical implications. Nitric Oxide. 2009;20:223-30

8. Tinajero-Trejo M, Jesse HE, Poole RK. Gasotransmitters, poisons, and antimicrobials: it's a gas, gas, gas! F1000Prime Rep 2013;5.

9. Motterlini R, Otterbein LE. The therapeutic potential of carbon monoxide. Nat Rev Drug Discov. 2010;9:728-43.

10. Carbon MBE. Monoxide: an essential signaling molecule. Med. Organomet Chem. 2010:247-85.

11. Kashfi K, Olson KR. Biology and therapeutic potential of hydrogen sulfide and hydrogen sulfide-releasing chimeras. Biochem Pharmacol. 2013;85:689-703.

12. Kajimura M, Fukuda R, Bateman RM, Yamamoto T, Suematsu M. Interactions of multiple gas-transducing systems: hallmarks and uncertainties of $\mathrm{CO}, \mathrm{NO}$, and $\mathrm{H}_{2} \mathrm{~S}$ gas biology. Antioxid Redox Signal. 2010;13:157-92.

13. Furne J, Saeed A, Levitt MD. Whole tissue hydrogen sulfide concentrations are orders of magnitude lower than presently accepted values. Am J Phys. 2008;295:1479-85.

14. Panthi S, Chung H-J, Jung J, Jeong NY. Physiological importance of hydrogen sulfide: emerging potent neuroprotector and neuromodulator. Oxidative Med Cell Longev. 2016;2016

15. Panthi S, Gautam K. Roles of nitric oxide and ethyl pyruvate after peripheral nerve injury. Inflamm Regen. 2017;37:20.

16. Shefa U, Yeo SG, Kim M-S, Song IO, Jung J, Jeong NY, et al. Role of Gasotransmitters in oxidative stresses, Neuroinflammation, and neuronal repair. Biomed Res Int. 2017;2017

17. Cirino G, Vellecco V, Bucci M. Nitric oxide and hydrogen sulfide: the gasotransmitter paradigm of the vascular system. Br J Pharmacol. 2017;

18. Qian Y, Matson JB. Gasotransmitter delivery via self-assembling peptides: treating diseases with natural signaling gases. Adv Drug Deliv Rev. 2017;110:137-56.

19. Szabo C. Gasotransmitters in cancer: from pathophysiology to experimental therapy. Nat Rev Drug Discov. 2016;15:185-203.

20. Knowles RG, Palacios M, Palmer RM, Moncada S. Formation of nitric oxide from L-arginine in the central nervous system: a transduction mechanism for stimulation of the soluble guanylate cyclase. Proc Natl Acad Sci. 1989;86:5159-62.

21. Garry PS, Ezra M, Rowland MJ, Westbrook J, Pattinson KTS. The role of the nitric oxide pathway in brain injury and its treatment-from bench to bedside. Exp Neurol. 2015;263:235-43.

22. Calabrese V, Mancuso C, Calvani M, Rizzarelli E, Butterfield DA, Stella AMG. Nitric oxide in the central nervous system: neuroprotection versus neurotoxicity. Nat Rev Neurosci. 2007;8:766-75.

23. Boissel J-P, Schwarz PM, Förstermann U. Neuronal-type NO synthase: transcript diversity and expressional regulation. Nitric Oxide. 1998;2:337-49.

24. Mustafa AK, Gadalla MM, Snyder SH. Signaling by gasotransmitters. Sci Signal. 2009;2:re2.

25. Garthwaite J, Boulton CL. Nitric oxide signaling in the central nervous system. Annu Rev Physiol. 1995;57:683-706.

26. Tieu K, Ischiropoulos H, Przedborski S. Nitric oxide and reactive oxygen species in Parkinson's disease. IUBMB Life. 2003;55:329-35.

27. Bredt DS, Glatt CE, Hwang PM, Fotuhi M, Dawson TM, Snyder SH. Nitric oxide synthase protein and mRNA are discretely localized in neuronal populations of the mammalian CNS together with NADPH diaphorase. Neuron. 1991;7:615-24.
28. Wang H-G, Lu F-M, Jin I, Udo H, Kandel ER, de Vente J, et al. Presynaptic and postsynaptic roles of $\mathrm{NO}, \mathrm{CGK}$, and RhoA in long-lasting potentiation and aggregation of synaptic proteins. Neuron. 2005;45:389-403.

29. Pautz A, Art J, Hahn S, Nowag S, Voss C, Kleinert H. Regulation of the expression of inducible nitric oxide synthase. Nitric Oxide. 2010;23:75-93.

30. Raju K, Ischiropoulos H. Gaseous Signaling in the Central Nervous System. Neurosci. 21st Century. 2016;1-16.

31. Chachlaki K, Garthwaite J, Prevot V. The gentle art of saying NO: how nitric oxide gets things done in the hypothalamus. Nat Rev Endocrinol. 2017;13:521.

32. Yamamoto K, Takei H, Koyanagi Y, Koshikawa N, Kobayashi M. Presynaptic cell type-dependent regulation of GABAergic synaptic transmission by nitric oxide in rat insular cortex. Neuroscience. 2015;284:65-77.

33. Yassin L, Radtke-Schuller S, Asraf H, Grothe B, Hershfinkel M, Forsythe ID, et al. Nitric oxide signaling modulates synaptic inhibition in the superior paraolivary nucleus (SPN) via CGMP-dependent suppression of KCC2. Front Neural Circuits. 2014;8

34. Puzzo D, Vitolo O, Trinchese F, Jacob JP, Palmeri A, Arancio O. Amyloid- $\beta$ peptide inhibits activation of the nitric oxide/cGMP/CAMP-responsive element-binding protein pathway during hippocampal synaptic plasticity. J Neurosci. 2005;25:6887-97.

35. Su K, Lin S, Wei J, Lee K, Zhao J, Shyue S, et al. The essential role of transient receptor potential vanilloid 1 in simvastatin-induced activation of endothelial nitric oxide synthase and angiogenesis. Acta Physiol. 2014;212: 191-204.

36. Greco R, Amantea D, Blandini F, Nappi G, Bagetta G, Corasaniti MT, et al. Neuroprotective effect of nitroglycerin in a rodent model of ischemic stroke: evaluation of Bcl-2 expression. Int Rev Neurobiol. 2007;82:423-35.

37. Khan M, Jatana M, Elango C, Paintlia AS, Singh AK, Singh I. Cerebrovascular protection by various nitric oxide donors in rats after experimental stroke. Nitric Oxide. 2006:15:114-24.

38. Iwanishi $K$, Watabe H, Hayashi T, Miyake $Y$, Minato $K$, lida H. Influence of residual oxygen-15-labeled carbon monoxide radioactivity on cerebral blood flow and oxygen extraction fraction in a dual-tracer autoradiographic method. Ann Nucl Med. 2009;23:363-71.

39. Toda N, Ayajiki K, Okamura T. Cerebral blood flow regulation by nitric oxide: recent advances. Pharmacol Rev. 2009;61:62-97.

40. Kielstein JT, Donnerstag F, Gasper S, Menne J, Kielstein A, MartensLobenhoffer J, et al. ADMA increases arterial stiffness and decreases cerebral blood flow in humans. Stroke. 2006;37:2024-9.

41. Kawamoto EM, Vasconcelos AR, Degaspari S, Böhmer AE, Scavone C, Marcourakis T. Age-related changes in nitric oxide activity, cyclic GMP, and TBARS levels in platelets and erythrocytes reflect the oxidative status in central nervous system. Age. 2013;35:331-42.

42. Biojone C, Cabrera Casarotto P, Regiane Joca S, Castren E. Interplay between nitric oxide and brain-derived neurotrophic factor in neuronal plasticity. CNS Neurol Disord Targets. 2015;14:979-87.

43. Kakizawa S, Yamazawa T, Chen Y, Ito A, Murayama T, Oyamada H, et al. Nitric oxide-induced calcium release via ryanodine receptors regulates neuronal function. EMBO J. 2012;31:417-28.

44. Lev-Ram V, Jiang T, Wood J, Lawrence DS, Tsien RY. Synergies and coincidence requirements between $\mathrm{NO}, \mathrm{CGMP}$, and ca $2+$ in the induction of cerebellar long-term depression. Neuron. 1997;18:1025-38.

45. Lev-Ram V, Wong ST, Storm DR, Tsien RY. A new form of cerebellar longterm potentiation is postsynaptic and depends on nitric oxide but not cAMP. Proc Natl Acad Sci. 2002;99:8389-93.

46. Katoh A, Kitazawa $H$, Itohara S, Nagao S. Inhibition of nitric oxide synthesis and gene knockout of neuronal nitric oxide synthase impaired adaptation of mouse optokinetic response eye movements. Learn Mem. 2000;7:220-6.

47. Gautier-Sauvigné S, Colas D, Parmantier P, Clement P, Gharib A, Sarda N, et al. Nitric oxide and sleep. Sleep Med Rev. 2005;9:101-13.

48. Džoljić $\mathrm{E}$, Grabatinić I, Kostić $\mathrm{V}$. Why is nitric oxide important for our brain? Funct Neurol. 2015;30:159-63.

49. Benarroch EE. Nitric oxide a pleiotropic signal in the nervous system. Neurology AAN Enterprises. 2011;77:1568-76.

50. Nakamura T, Gu Z, Lipton SA. Contribution of glutamatergic signaling to nitrosative stress-induced protein misfolding in normal brain aging and neurodegenerative diseases. Aging Cell. 2007;6:351-9.

51. Edwards TM, Rickard NS. New perspectives on the mechanisms through which nitric oxide may affect learning and memory processes. Neurosci Biobehav Rev. 2007;31:413-25. 
52. Lüth $\mathrm{H}-\mathrm{J}$, Münch $\mathrm{G}$, Arendt T. Aberrant expression of NOS isoforms in Alzheimer's disease is structurally related to nitrotyrosine formation. Brain Res. 2002;953:135-43.

53. Malinski T. Nitric oxide and nitroxidative stress in Alzheimer's disease. J Alzheimers Dis. 2007;11:207-18.

54. Virarkar M, Alappat L, Bradford PG, Awad AB. L-arginine and nitric oxide in CNS function and neurodegenerative diseases. Crit Rev Food Sci Nutr. 2013; 53:1157-67.

55. Huang Z, Huang PL, Ma J, Meng W, Ayata C, Fishman MC, et al. Enlarged infarcts in endothelial nitric oxide synthase knockout mice are attenuated by nitro-L-arginine. J Cereb Blood Flow Metab. 1996;16:981-7.

56. Lundblad C, Grände P-O, Bentzer P. Hemodynamic and histological effects of traumatic brain injury in eNOS-deficient mice. J Neurotrauma. 2009;26: 1953-62.

57. Robertson CS, Gopinath SP, Valadka AB, Van M, Swank PR, Goodman JC. Variants of the endothelial nitric oxide gene and cerebral blood flow after severe traumatic brain injury. J Neurotrauma. 2011:28:727-37.

58. Dezfulian C, Alekseyenko A, Dave KR, Raval AP, Do R, Kim F, et al. Nitrite therapy is neuroprotective and safe in cardiac arrest survivors. Nitric Oxide. 2012;26:241-50

59. Ichinose F. Improving outcomes after cardiac arrest using NO inhalation. Trends Cardiovasc Med. 2013;23:52-8.

60. Terpolilli NA, Kim S-W, Thal SC, Kuebler WM, Plesnila N. Inhaled nitric oxide reduces secondary brain damage after traumatic brain injury in mice. J Cereb Blood Flow Metab. 2013;33:311-8.

61. Terpolilli NA, Kim S-W, Thal SC, Kataoka H, Zeisig V, Nitzsche B, et al. Inhalation of nitric oxide prevents ischemic brain damage in experimental stroke by selective dilatation of collateral arterioles. Circ Res. 2011; Circresaha-111

62. Zhang F, White JG, ladecola C. Nitric oxide donors increase blood flow and reduce brain damage in focal ischemia: evidence that nitric oxide is beneficial in the early stages of cerebral ischemia. J Cereb Blood Flow Metab. 1994;14:217-26.

63. Jung K-H, Chu K, Ko S-Y, Lee S-T, Sinn D-I, Park D-K, et al. Early intravenous infusion of sodium nitrite protects brain against in vivo ischemia-reperfusion injury. Stroke. 2006;37:2744-50.

64. Morikawa E, Moskowitz MA, Huang Z, Yoshida T, Irikura K, Dalkara T. L-arginine infusion promotes nitric oxide-dependent vasodilation, increases regional cerebral blood flow, and reduces infarction volume in the rat. Stroke. 1994;25: 429-35.

65. Li Y-S, Shemmer B, Stone E, Nardi MA, Jonas S, Quartermain D. Neuroprotection by inhaled nitric oxide in a murine stroke model is concentration and duration dependent. Brain Res. 2013;1507:134-45.

66. Fathi AR, Pluta RM, Bakhtian KD, Qi M, Lonser RR. Reversal of cerebral vasospasm via intravenous sodium nitrite after subarachnoid hemorrhage in primates. J Neurosurg. 2011;115:1213-20.

67. Pluta R, Dejam AA, Gladwin M, Oldfiled E. Nitrite infusions prevent delayed cerebral vasospasm in a primate model of subarachnoid hemorrhage. Free Radic Biol Med. 2004;37:S81.

68. Shiva S. Nitrite: a physiological store of nitric oxide and modulator of mitochondrial function. Redox Biol. 2013;1:40-4.

69. Olivier $\mathrm{P}$, Loron $\mathrm{G}$, Fontaine $\mathrm{RH}$, Pansiot J, Dalous J, Thi HP, et al. Nitric oxide plays a key role in myelination in the developing brain. J Neuropathol Exp Neurol. 2010;69:828-37.

70. Brown GC. Nitric oxide and neuronal death. Nitric Oxide. 2010;23:153-65

71. Huang Z, Huang PL, Panahian N, Dalkara T, Fishman MC, Moskowitz MA. Effects of cerebral ischemia in mice deficient in neuronal nitric oxide synthase. Sci. 1994:1883.

72. Baruch K, Kertser A, Porat Z, Schwartz M. Cerebral nitric oxide represses choroid plexus NFKB-dependent gateway activity for leukocyte trafficking. EMBO J. 2015:34:1816-28.

73. P Fernandez A, Pozo-Rodrigalvarez A, Serrano J, Martinez-Murillo R. Nitric oxide: target for therapeutic strategies in Alzheimer's disease. Curr Pharm Des. 2010:16:2837-50.

74. de Souza KPR, Silva EG, de Oliveira Rocha ES, Figueiredo LB, de AlmeidaLeite CM, Arantes RME, et al. Nitric oxide synthase expression correlates with death in an experimental mouse model of dengue with CNS involvement. Virol J. 2013;10:267.

75. Yuste JE, Tarragon E, Campuzano CM, Ros-Bernal F. Implications of glial nitric oxide in neurodegenerative diseases. Front Cell Neurosci. 2015;9

76. Kimura H, Nagai Y, Umemura K, Kimura Y. Physiological roles of hydrogen sulfide: synaptic modulation, neuroprotection, and smooth muscle relaxation. Antioxid Redox Signal. 2005;7:795-803.
77. Zhang J, Ding Y, Wang Z, Kong Y, Gao R, Chen G. Hydrogen sulfide therapy in brain diseases: from bench to bedside. Med Gas Res. 2017:7:113.

78. Qu K, Lee SW, Bian JS, Low C-M, Wong PT-H. Hydrogen sulfide: neurochemistry and neurobiology. Neurochem Int. 2008;52:155-65.

79. Chen $\mathrm{X}$, Jhee $\mathrm{KH}$, Kruger WD. Production of the neuromodulator $\mathrm{H} 2 \mathrm{~S}$ by cystathionine beta-synthase via the condensation of cysteine and homocysteine. J Biol Chem. 2004;279:52082-6.

80. Stipanuk MH, Beck PW. Characterization of the enzymic capacity for cysteine desulphhydration in liver and kidney of the rat. Biochem J. 1982;206:267-77.

81. Li L, Moore PK. Putative biological roles of hydrogen sulfide in health and disease: a breath of not so fresh air? Trends Pharmacol Sci. 2008;29:84-90.

82. Mikami Y, Shibuya N, Kimura Y, Nagahara N, Ogasawara Y, Kimura H. Thioredoxin and dihydrolipoic acid are required for 3-mercaptopyruvate sulfurtransferase to produce hydrogen sulfide. Biochem J. 2011;439:479-85.

83. Tang S, Huang D, An N, Chen D, Zhao D. A novel pathway for the production of $\mathrm{H}_{2} \mathrm{~S}$ by DAO in rat jejunum. Neurogastroenterol Motil. 2016;

84. Shibuya N, Koike S, Tanaka M, Ishigami-Yuasa M, Kimura Y, Ogasawara Y, et al. A novel pathway for the production of hydrogen sulfide from D-cysteine in mammalian cells. Nat Commun. 2013:4:1366.

85. Polhemus DJ, Lefer DJ. Emergence of hydrogen sulfide as an endogenous gaseous signaling molecule in cardiovascular disease. Circ Res. 2014;114:730-7.

86. Kolluru GK, Shen X, Bir SC, Kevil CG. Hydrogen sulfide chemical biology: pathophysiological roles and detection. Nitric Oxide. 2013;35:5-20.

87. Streeter $\mathrm{E}, \mathrm{Ng} \mathrm{HH}$, Hart JL. Hydrogen sulfide as a vasculoprotective factor. Med. Gas Res. 2013:3:9.

88. Hermann A, Sitdikova GF, Weiger TM. Gasotransmitters: Physiology and Pathophysiology. 2012

89. Tan BH, Wong PT-H, Bian J-S. Hydrogen sulfide: a novel signaling molecule in the central nervous system. Neurochem Int. 2010;56:3-10.

90. Gong Q-H, Wang Q, Pan L-L, Liu X-H, Huang H, Zhu Y-Z. Hydrogen sulfide attenuates lipopolysaccharide-induced cognitive impairment: a pro-inflammatory pathway in rats. Pharmacol Biochem Behav. 2010;96:52-8.

91. Tang X, Yang C, Chen J, Yin W, Tian S, Hu B, et al. Effect of hydrogen sulphide on $\beta$-amyloid-induced damage in PC12 cells. Clin Exp Pharmacol Physiol. 2008;35:180-6

92. Fan H, Guo Y, Liang X, Yuan Y, Qi X, Wang M, et al. Hydrogen sulfide protects against amyloid beta-peptide induced neuronal injury via attenuating inflammatory responses in a rat model. J Biomed. 2013;27:296.

93. Xuan A, Long D, Li J, Ji W, Zhang $M$, Hong L, et al. Hydrogen sulfide attenuates spatial memory impairment and hippocampal neuroinflammation in beta-amyloid rat model of Alzheimer's disease. J Neuroinflammation. 2012;9:202.

94. Eto K, Asada T, Arima K, Makifuchi T, Kimura H. Brain hydrogen sulfide is severely decreased in Alzheimer's disease. Biochem Biophys Res Commun. 2002;293:1485-8.

95. Zhang L-M, Jiang C-X, Liu D-W. Hydrogen sulfide attenuates neuronal injury induced by vascular dementia via inhibiting apoptosis in rats. Neurochem Res. 2009:34:1984-92.

96. Giuliani D, Ottani A, Zaffe D, Galantucci M, Strinati F, Lodi R, et al. Hydrogen sulfide slows down progression of experimental Alzheimer's disease by targeting multiple pathophysiological mechanisms. Neurobiol Learn Mem. 2013;104:82-91.

97. Schreier SM, Muellner MK, Steinkellner H, Hermann M, Esterbauer H, Exner $M$, et al. Hydrogen sulfide scavenges the cytotoxic lipid oxidation product 4-HNE. Neurotox Res. 2010;17:249-56.

98. Kida K, Ichinose F. Hydrogen sulfide and neuroinflammation. Chem Biochem Pharmacol Hydrog Sulfide. 2015:181-9.

99. Kida K, Yamada M, Tokuda K, Marutani E, Kakinohana M, Kaneki M, et al. Inhaled hydrogen sulfide prevents neurodegeneration and movement disorder in a mouse model of Parkinson's disease. Antioxid Redox Signal. 2011;15:343-52.

100. Hu L, Lu M, Tiong CX, Dawe GS, Hu G, Bian J. Neuroprotective effects of hydrogen sulfide on Parkinson's disease rat models. Aging Cell. 2010;9:135-46.

101. Xie L, Hu L-F, Teo XQ, Tiong CX, Tazzari $V$, Sparatore A, et al. Therapeutic effect of hydrogen sulfide-releasing L-Dopa derivative ACS84 on 6-OHDAinduced Parkinson's disease rat model. PLoS One. 2013:8:e60200.

102. Cao X, Cao L, Ding L, Bian J. A new hope for a devastating disease: hydrogen sulfide in Parkinson's disease. Mol Neurobiol. 2017:1-11.

103. Karimi SA, Hosseinmardi N, Janahmadi M, Sayyah M, Hajisoltani R. The protective effect of hydrogen sulfide $\left(\mathrm{H}_{2} \mathrm{~S}\right)$ on traumatic brain injury (TBI) induced memory deficits in rats. Brain Res Bull. 2017;134:177-82.

104. Borgens R. Ben, Liu-Snyder P. Understanding secondary injury Q Rev Biol. 2012;87:89-127. 
105. Mustafa AG, Alshboul OA. Pathophysiology of traumatic brain injury. Neurosci. 2013;18:222-34.

106. Homsi S, Federico F, Croci N, Palmier B, Plotkine M, Marchand-Leroux C, et al. Minocycline effects on cerebral edema: relations with inflammatory and oxidative stress markers following traumatic brain injury in mice. Brain Res. 2009;1291:122-32.

107. Zhang M, Shan H, Wang T, Liu W, Wang Y, Wang L, et al. Dynamic change of hydrogen sulfide after traumatic brain injury and its effect in mice. Neurochem Res. 2013;38:714-25.

108. Dai H-B, Xu M-M, Lv J, Ji X-J, Zhu S-H, Ma R-M, et al. Mild hypothermia combined with hydrogen sulfide treatment during resuscitation reduces hippocampal neuron apoptosis via NR2A, NR2B, and PI3K-Akt signaling in a rat model of cerebral ischemia-reperfusion injury. Mol Neurobiol. 2016;53:4865-73.

109. Li T, Liu H, Xue H, Zhang J, Han X, Yan S, et al. Neuroprotective effects of hydrogen sulfide against early brain injury and secondary cognitive deficits following subarachnoid hemorrhage. Brain Pathol. 2016;

110. Yonezawa D, Sekiguchi F, Miyamoto M, Taniguchi E, Honjo M, Masuko T, et al. A protective role of hydrogen sulfide against oxidative stress in rat gastric mucosal epithelium. Toxicology. 2007;241:11-8.

111. Chu Q-J, He L, Zhang W, Liu C-L, Ai Y-Q, Zhang Q. Hydrogen sulfide attenuates surgical trauma-induced inflammatory response and cognitive deficits in mice. J Surg Res. 2013;183:330-6.

112. Zhang M, Shan H, Chang P, Wang T, Dong W, Chen X, et al. Hydrogen sulfide offers neuroprotection on traumatic brain injury in parallel with reduced apoptosis and autophagy in mice. PLoS One. 2014;9:e87241.

113. Paul BD, Sbodio Jl, Xu R, Vandiver MS, Cha JY, Snowman AM, et al. Cystathionine gamma-lyase deficiency mediates neurodegeneration in Huntington's disease. Nature. 2014;509:96-100.

114. Paul BD, Snyder SH. Role Of neuronal signaling effector hydrogen sulfide (H2S) and sulfhydration in Huntington's disease. FASEB J. 2016;30:1271-6.

115. Kimura H, Shibuya N, Kimura Y. Hydrogen sulfide is a signaling molecule and a cytoprotectant. Antioxid Redox Signal. 2012;17:45-57.

116. Deng J, Lei C, Chen Y, Fang Z, Yang Q, Zhang H, et al. Neuroprotective gases-fantasy or reality for clinical use? Prog Neurobiol. 2014;115:210-45.

117. Mikami Y, Shibuya N, Kimura Y, Nagahara N, Yamada M, Kimura H. Hydrogen sulfide protects the retina from light-induced degeneration by the modulation of Ca2+ influx. J Biol Chem. 2011;286:39379-86.

118. Kimura H. The physiological role of hydrogen sulfide and beyond. Nitric Oxide. 2014;41:4-10

119. Abe K, Kimura H. The possible role of hydrogen sulfide as an endogenous neuromodulator. J Neurosci. 1996;16:1066-71.

120. Lee SW, Hu Y-S, Hu L-F, Lu Q, Dawe GS, Moore PK, et al. Hydrogen sulphide regulates calcium homeostasis in microglial cells. Glia. 2006;54:116-24.

121. Geng B, Chang L, Pan C, Qi Y, Zhao J, Pang Y, et al. Endogenous hydrogen sulfide regulation of myocardial injury induced by isoproterenol. Biochem Biophys Res Commun. 2004;318:756-63.

122. White BJO. The vascular effects of hydrogen sulphide. 2012

123. Wang R. Shared signaling pathways among gasotransmitters. Proc Natl Acad Sci. 2012:109:8801-2.

124. Coletta C, Papapetropoulos A, Erdelyi K, Olah G, Módis K, Panopoulos P, et al. Hydrogen sulfide and nitric oxide are mutually dependent in the regulation of angiogenesis and endothelium-dependent vasorelaxation. Proc Natl Acad Sci. 2012;109:9161-6.

125. Olson KRA. Practical look at the chemistry and biology of hydrogen sulfide. Antioxid Redox Signal. 2012;17:32-44.

126. Nagpure BV, Interaction BJ-S. Of hydrogen sulfide with nitric oxide in the cardiovascular system. Oxidative Med Cell Longev. 2015;2016

127. Furchgott RF, Jothianandan D. Endothelium-dependent and-independent vasodilation involving cyclic GMP: relaxation induced by nitric oxide, carbon monoxide and light. J Vasc Res. 1991;28:52-61.

128. Taoka S, Banerjee R. Characterization of NO binding to human cystathionine $\beta$-synthase:: Possible implications of the effects of $\mathrm{CO}$ and $\mathrm{NO}$ binding to the human enzyme. J Inorg Biochem. 2001;87:245-51.

129. Zhao W, Zhang J, Lu Y, Wang R. The vasorelaxant effect of $H(2) S$ as a novel endogenous gaseous K(ATP) channel opener. EMBO J. 2001;20:6008-16.

130. Beltowski J, Jamroz-Wiśnniewska A. Hydrogen sulfide and endotheliumdependent vasorelaxation. Molecules. 2014;19:21506-28.

131. Broos K, Feys HB, De Meyer SF, Vanhoorelbeke K, Deckmyn H. Platelets at work in primary hemostasis. Blood Rev. 2011;25:155-67.

\section{Submit your next manuscript to BioMed Central and we will help you at every step:}

- We accept pre-submission inquiries

- Our selector tool helps you to find the most relevant journal

- We provide round the clock customer support

- Convenient online submission

- Thorough peer review

- Inclusion in PubMed and all major indexing services

- Maximum visibility for your research

Submit your manuscript at www.biomedcentral.com/submit
C Biomed Central 